\title{
GUILLAIN BARRÉ SYNDROME IN A POPULATION LESS THAN 15 YEARS OLD IN BRAZIL
}

\author{
Elza Dias-Tosta', Carlos Santos Kückelhaus
}

ABSTRACT - To know the impact of the Guillain Barré syndrome (GBS) in the population less than 15 years old,
after the eradication of poliomyelitis. Data bank from the program of epidemiological surveillance of acute
flaccid palsies (AFP) from the Fundação Nacional de Saúde were analyzed between $1990-1996$. From 3619
notifications of AFP there were 1678 GBS. GBS yearly incidence rates is $0.39-0.63$ cases $/ 100,000$. No consistent
seasonal variation existed or relationship to vaccines. Weakness at inclusion were, moderate $52.1 \%$, severe in
$47.9 \%$, sixty days after $57.1 \%$ normal, $7.4 \%$ mild, $15.7 \%$ moderate, $10.4 \%$ with severe deficits, death in $5.4 \%$.
$67(4.0 \%)$ cases unknown. Death rates varies from $2.8 \%$ in southeast to $7.9 \%$ in the northeast. GBS was the
most frequent cause of AFP. In spite of the severity of this disease being similar in the different regions, the
outcome varies according to origin of the cases, possibly reflecting the economical conditions in those places.

KEY WORDS: Guillain Barré syndrome, epidemiology, vaccines, follow up.

\begin{abstract}
Síndrome de Guillain-Barré na população menor de quinze anos no Brasil
RESUMO - Com o objetivo de conhecer a importância da síndrome de Guillain Barré (SGB) na população menor de quinze anos, após a erradicação da poliomielite, foi analizado o banco de dados do programa da vigilância epidemiológica das paralisias agudas e flácidas (PAF) da Fundação Nacional de Saúde, entre 1990 e 1996. De 3619 notificações de PAF encontraram-se 1678 com SGB, com incidência anual de 0,39-0,63 casos/ 100.000. Não se comprovou variação sazonal nem relação com a vacina. Os casos eram de acometimento: moderado em 52,1\%, grave em 47,9\%, 60 dias após 57,1\% eram normais, 7,4\% leves, 15,7\% moderados, $10,4 \%$ graves, morte em 5,4\%, $67(4,0 \%)$ casos perdidos para o acompanhamento. Mortes ocorreram em $2,8 \%$ no sudeste, e $7,9 \%$ no nordeste. SGB é a causa mais frequente de PAF. Embora a gravidade da doença seja semelhante nas diferentes regiões, a evolução varia conforme o local de origem, possivelmente refletindo diferentes condições econômicas.
\end{abstract}

PALAVRAS-CHAVE: síndrome de Guillain Barré, epidemiologia, vacina, evolução.

The acute flaccid palsies (AFP) are a group of diseases, with many etiologies, variable incidences and variable prognoses, that affect population around the year in the world. Until mid 80's the acute poliomyelitis was the main cause of acute flaccid palsies but with the program of eradication of poliomyelitis had emerged the Guillain-Barré syndrome (GBS) as the major etiology, such statement is already proved in the developed countries, but still unknown in many communities. The epidemiological data has been shown valuable in evaluating the frequency of GBS in various populations, studying changes in incidence over time, detecting outbreaks or cluster of unusual preceding illnesses, and possible illuminating underlying causes ${ }^{1,2}$. Epidemiological surveillance of GBS is considerable relevant since large and small epidemics due to vaccines, water pollution, drugs, as well unexpected statistically significant variations in annual incidence in age sub-groups have been reported $^{3}$.

The Brazilian national program of immunization against poliomyelitis since 1980, has afforded two important goals: the eradication of this disease in 1989, and a better understanding of the incidence and clinical expression of acute flaccid paralysis in children less than 15 years old, due to the epidemiological surveillance which has been carried out since then.

Our goal was to know the impact of the GBS in the population less than 15 years old, after the eradication of poliomyelitis, with analysis of the incidence of this syndrome in that particular age group in the Brazil as a whole, and in the five macro geographic regions in the country. The epidemiological studies

${ }^{1} \mathrm{MD}, \mathrm{PhD}$, Head of Neurology Unit, Hospital de Base do Distrito Federal, Brasilia DF, Brazil; ${ }^{2} \mathrm{MD}$, Neurologist of Hospital Regional do Guará, Brasília DF, Brazil.

Received 27 August 2001, received in final form 26 November 2001. Accepted 5 December 2001.

Dra. Elza Dias Tosta - SHIS QL16 CONJ. 5 CASA 17 Lago Sul - 71640-255 Brasília DF - Brasil. 
were done to understand if there were peak of incidence along the years analyzed, its relationship with vaccination campaigns, the sex preponderance and the possible influence, as a predictive factor, of the patient's ages, as age at onset may be relevant in differentiating clinicoepidemiological subgroups ${ }^{3}$ and the length of prodromal period and the severity of the clinical patterns at the first examination and sixty days later.

\section{METHOD}

A total of 3619 cases of acute flaccid paralysis were notified during the poliomyelitis surveillance program carried out by the Brazilian health authorities, during the period of 1990 to 1996, in a population under 15 years old, as recorded by the Fundação Nacional de Saúde of the Brazilian Ministry of Health.

The Guillain-Barré syndrome was diagnosed according to the clinical criteria defined by Asbury \& Cornblath ${ }^{4}$ : presence of roughly symmetrical motor weakness over a period ranging from days to 4 weeks, and decrease or disappearance of deep tendon reflexes.

We separated two subgroups of patients according to the deficit found at the first examination in order to know if there were a form of predicting their evolution. The severity of the motor deficit was characterized as moderate when two limbs were weak at the first examination and severe when more than two limbs were involved or respiratory insufficiency was present. Sixty days later all the patients had a second examination, and was reported if there was any persistent motor weakness as mild, moderated or severe. The presence and severity of the sequels were classified as absent (those with no motor deficits), mildly (minimal motor deficit in one limb or reflex loss), moderated (motor deficits of more magnitude in more than one limb), or severe (severe motor deficits). Those ca- ses that could not be followed were classified as unknown.

Patients were also studied according to length of the time of disease installation defined as onset of weakness after the prodromal signs or preceding events in three groups: 0 to 7 days, 8 to 14 days and more than 15 days. The cases were also analyzed according their gender, ages and region of origin.

To gain a better understanding about the geographical distribution of the disease, the observations were referred to the five Brazilian macro-regions (north, northeast, middle west, southeast and south) and the incidence rates were calculated as the total number of cases/population less than 15 years old in that year $x 100000$. The mean coefficient of incidence were calculated as mean of the total number of cases in 7 years / mean of the population less than 15 years old from that region in 7 years $\mathrm{x} 100000$.

\section{RESULTS}

Within the 3619 cases of AFP, were found 78 cases (2\%) of polio post-vaccination, 33 cases (1\%) of trauma, $32(1 \%)$ of tumor, 126 cases (3\%) of myelitis, 1153 (32\%) others (such as encephalitis, cerebro-vascular events and cerebellar ataxia which are important differential diagnosis of gait disturbance), 506 (14\%) without diagnostic definition. There were initially 1742 cases of GBS reported; from these 51 could not afford a critical analysis and we could not agree with the diagnosis, so remained 1691 cases in the study. It was also not considered another 13 cases that although had evolution compatible with GBS, in the first examination it was not reported a symmetrical weakness of the limbs ${ }^{4}$. It remained 1678 cases (46\%) as Guillain-Barré syndrome.

From the total cases of Guillain-Barré recorded, $33.7 \%$ were notified in Brazilian southeast region,

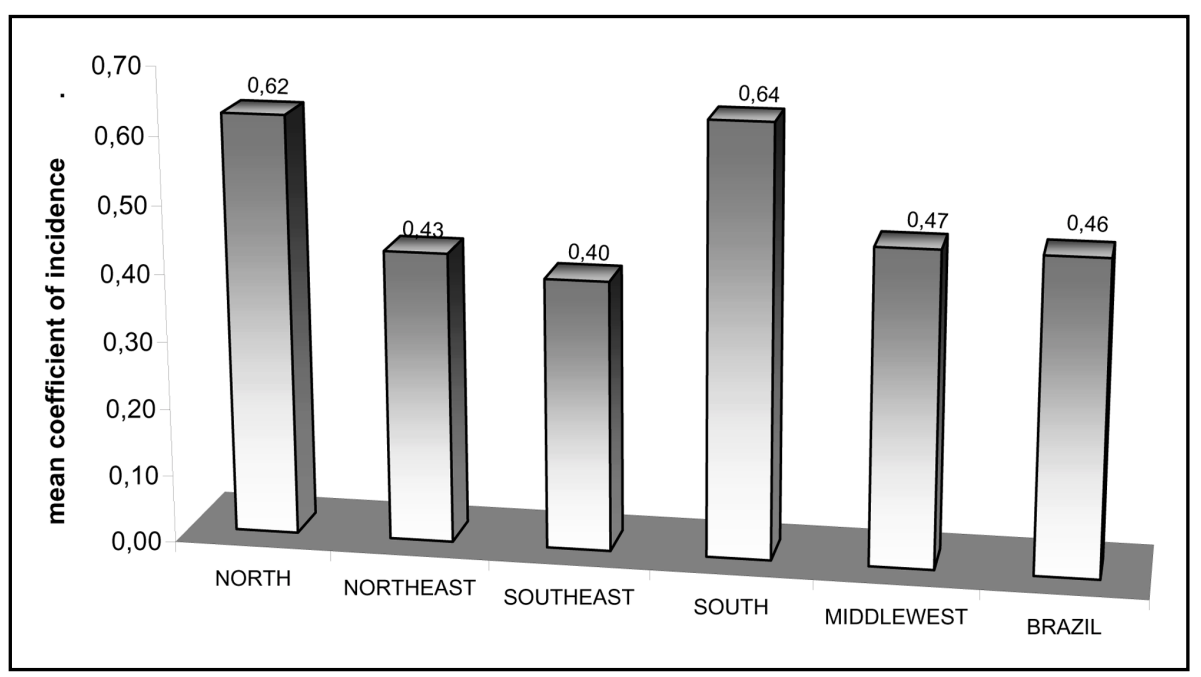

Fig 1. There is little variation between the mean coefficient of incidence of GBS cases in the macro-regions during the seven years studied. 


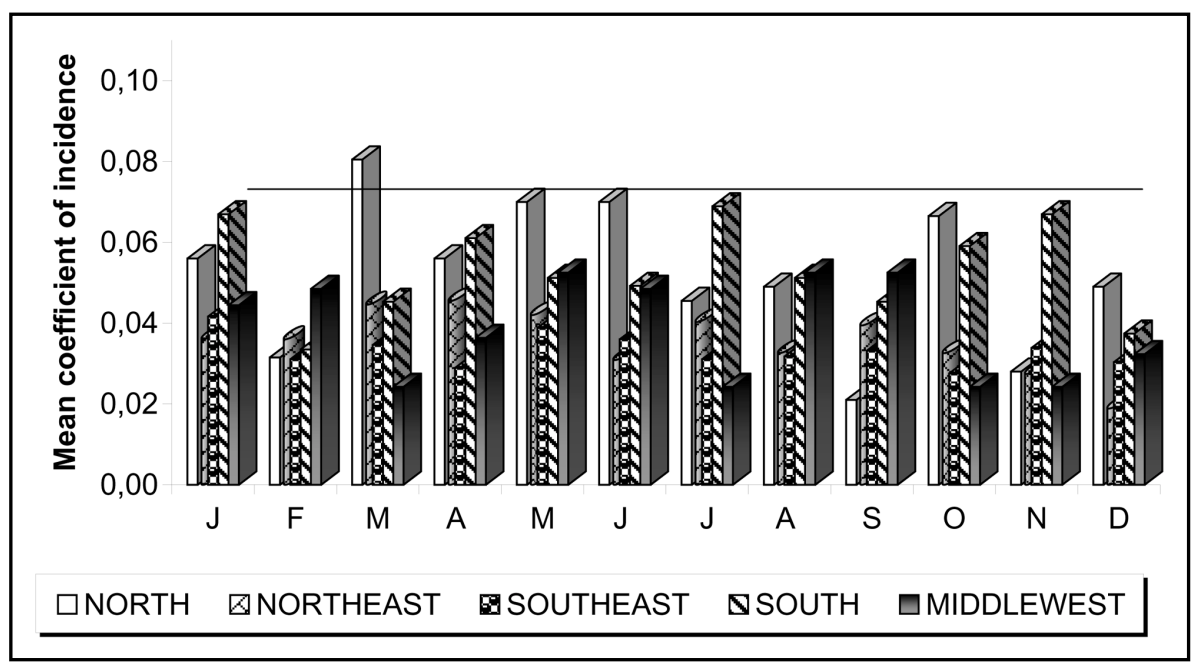

Fig 2. The analysis of cumulative data of GBS cases by month and regions shows a higher than 0.07 mean coefficient in North region (March, May and June) and South region (July).

Table 1. Analyses of mean coefficient of incidence by regions.

\begin{tabular}{lcc}
\hline Months & Region & Mean coefficient \\
\hline October/90 & North & $>0.21$ \\
April, May and June/91 & South & $>0.10$ \\
May, October/92 & North & $>0.13$ \\
July/92 & South & $>0.11$ \\
May/93 & Middlewest & $>0.14$ \\
March/94 & North & $>0.16$ \\
May/94 & North & $>0.14$ \\
April/95 & North & $>0.15$ \\
January/96 & North & $>0.15$ \\
October/96 & South & $>0.13$ \\
\hline
\end{tabular}

$29.6 \%$ in northeast, $19.2 \%$ in south, $10.6 \%$ in north and $6.9 \%$ in the middle west. When analyzed according to the demographic data the mean incidence rates show as a rather uniform distribution throughout the different macro-regions of Brazil such as southeast with $17 \%$, northeast $18 \%$, middle-west $19 \%$, north $26 \%$, south $27 \%$. The mean coefficient of incidence for the whole country was 0.46 , the same coefficient for the south region 0.64 , north 0.62 , middle-west 0.47 , northeast 0.43 , southeast 0.40 (Fig 1 ).

When the data from the whole country were studied along the 7 years (1990-1996), there was no clear peak distribution amongst the months, but there is only a variation in January and May, without much discrepancy in the visual analysis of the graphic. The cumulative data from 1990 to 1996 from the macro- regions distribution by months showed a mean coefficient above 0.07 in the north region during the months March, May and June (Fig 2). The same is seen in the south region in July. To be sure that these peaks were not due to small cumulative differences but to a very well defined peak, the more accurate analysis were processed by regions by months from each year. There were peaks $>0.21$ in the north region in October 1990, and middle west in May 1993 and greater than 0.1 in other regions and months during the years of study (Table 1).

The month analyses showed repeated peaks of incidence in May (once in the south, twice in north and middle west regions), April (south and north regions) and October (in the north region twice and once in the south region). The data were compared with the anti-poliomyelitis vaccination calendar in order to test if the peaks could be temporally related to cases of GBS recorded. There was no clear increment temporally related with the vaccine campaign, considering either 3 or 6 weeks after the vaccination when Brazil was studied as a whole, each year, during the 7 years analyzed (Fig 3). We also tested if there was any increase in a specific region that could be diluted in the data from the whole country, specifically the north region, the south region and the middle west region. We found indeed in the north region the increment after the third vaccination campaign in 1990, after the first one in 1992 and after the first, the second and the third campaigns in 1993 and also after the first vaccination campaign in 1994. In the south region there were an increase incidence in 1994 after the third campaign. However there was no regularity in the behavior in those increments to 


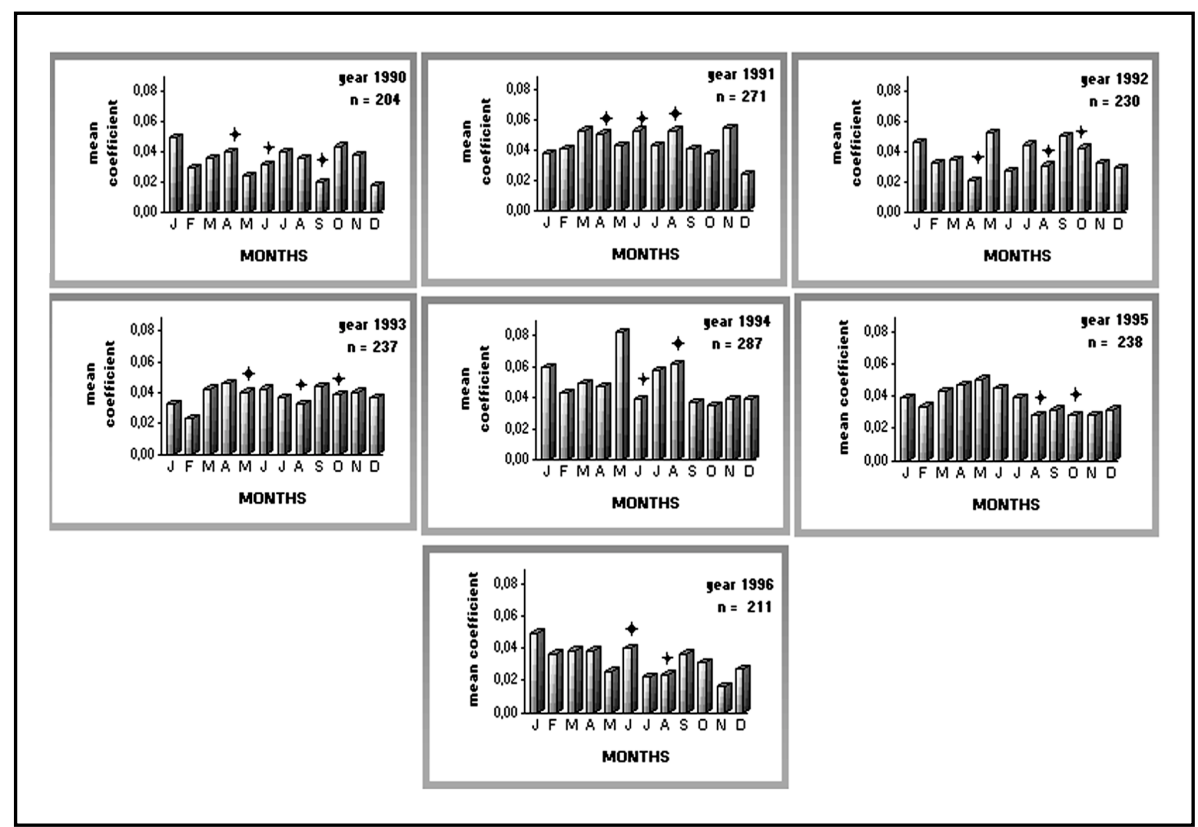

Fig 3. The Graphic analysis show that there is no correlation between the means of incidence and the vaccination campaing considering either three or six weeks after the vacination. +, Sabin vaccination campaign.

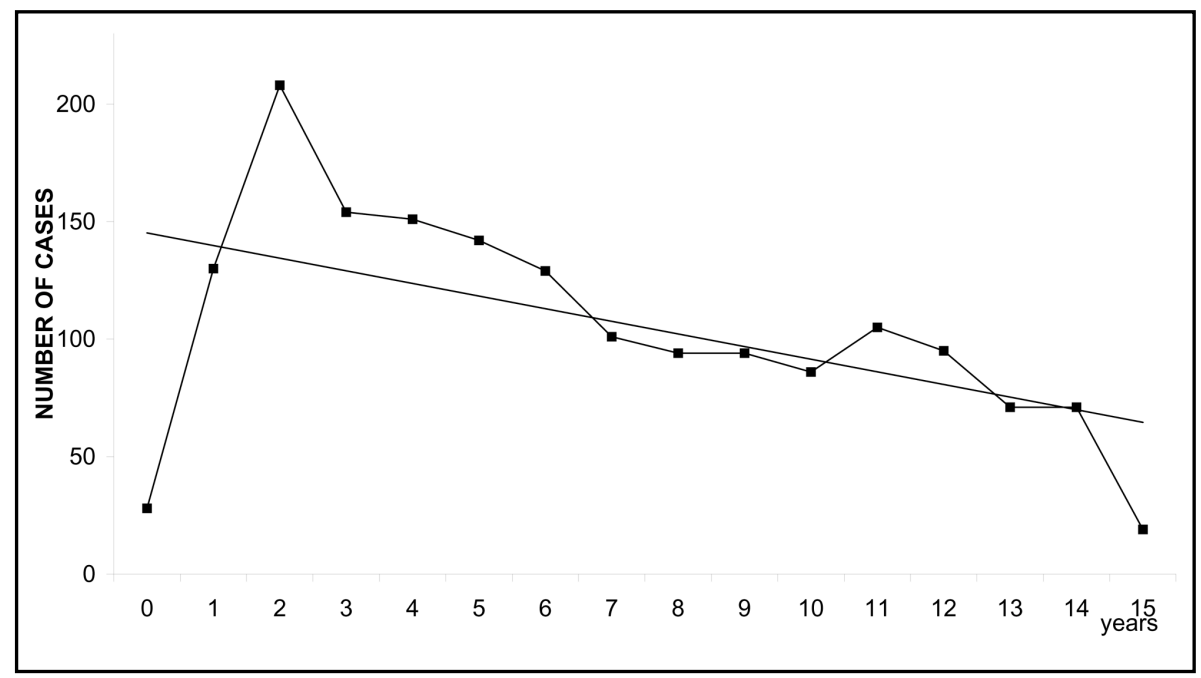

Fig 4. This graphic shows a higher incidence of GBS cases at two years old (0-4 years).

suggest events temporally related. Some of those peaks after vaccination campaign could be explained as greater awareness from the authorities and the population with increase in notification. Other increments were not related to the vaccination campaign, as those in the south region (1991), in the north region in 1990 and 1992, in the middle west region in 1993 and in October in the north region in 1990 and 1992 and in the south region in 1996. Those regions are very different in the climate and social-economic conditions, so it is at present difficult to make any correlation with the increasing in- cidence of GBS in those regions mainly if they have not occurred at the same time.

The cases of Guillain-Barré syndrome were more frequently related among children aging 0-4 years $(n=671)$, peaking 2 years old, followed by the group of 5-9 years old $(n=560)$, and those older than nine $(\mathrm{n}=447)$ (Fig 4).

A slight preponderance of boys (55\%) was observed throughout the years of the study.

At the entry of the study from 1678 cases, $52 \%$ were characterized as moderately affected and $48 \%$ as severely affected. At the follow-up sixty days la- 


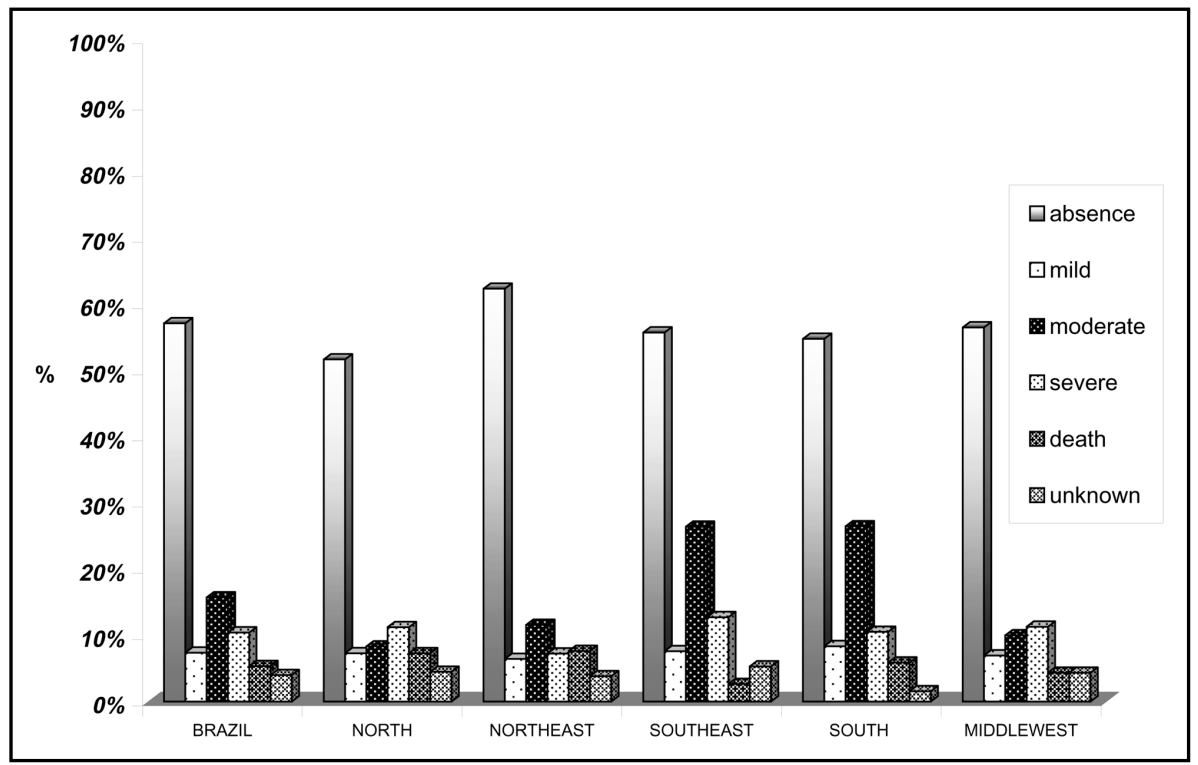

Fig 5. Follow up of 1678 cases of GBS from 1990 to 1996 grouped by regions. Examination after 60 days of entry.

Table 2. Follow up: comparison on the severity of cases at 60 days and severity at first examination, ages at entry and prodromal times.

\begin{tabular}{|c|c|c|c|c|c|c|c|c|}
\hline & & \multicolumn{7}{|c|}{ Examination at 60 days } \\
\hline & & $\mathrm{n}$ & Absence \% & Mild \% & Moderate \% & Severe \% & Death \% & Unknown \% \\
\hline \multirow{4}{*}{$\begin{array}{l}\text { Severity } \\
\text { at first } \\
\text { examination }\end{array}$} & Moderate & 874 & $566(64,8 \%)$ & $72(8,2 \%)$ & $121(13,8 \%)$ & $54(6,2 \%)$ & $27(3,1 \%)$ & $34(3,9 \%)$ \\
\hline & Severe & 804 & $393(48,9 \%)$ & $52(6,5 \%)$ & $142(17,7 \%)$ & $121(15,0 \%)$ & $63(7,8 \%)$ & $33(4,1 \%)$ \\
\hline & & 1678 & & & & & & \\
\hline & $0-4$ years & 671 & $392(58,4 \%)$ & $52(7,7 \%)$ & $112(16,7 \%)$ & $50(7,5 \%)$ & $36(5,4 \%)$ & $29(4,3 \%)$ \\
\hline \multirow[t]{3}{*}{ Age } & 5-9 years & 560 & $330(58,9 \%)$ & $38(6,8 \%)$ & $78(13,9 \%)$ & $62(11,1 \%)$ & $36(6,4 \%)$ & $16(2,9 \%)$ \\
\hline & $10-15$ years & 447 & $237(53,0 \%)$ & $33(7,4 \%)$ & $74(16,6 \%)$ & $63(14,1 \%)$ & $18(4,0 \%)$ & $22(4,9 \%)$ \\
\hline & & 1678 & & & & & & \\
\hline \multirow{4}{*}{$\begin{array}{l}\text { Prodromal } \\
\text { time }\end{array}$} & O to 7 days & 1471 & $840(57,1 \%)$ & $106(7,2 \%)$ & $233(15,8 \%)$ & $153(10,4 \%)$ & $81(5,5 \%)$ & $58(3,9 \%)$ \\
\hline & 8 to 14 days & 109 & $58(53,2 \%)$ & $8(7,3 \%)$ & $19(17,4 \%)$ & $13(11,9 \%)$ & $5(4,6 \%)$ & $6(5,5 \%)$ \\
\hline & $>15$ days & 98 & $61(62,2 \%)$ & $10(10,2 \%)$ & $11(11,2 \%)$ & $9(9,2 \%)$ & $4(4,1 \%)$ & $3(3,1 \%)$ \\
\hline & & 1678 & & & & & & \\
\hline
\end{tabular}

ter 57.1 of the patient were free from symptoms or signs of Guillain-Barré syndrome, $7.4 \%$ had mild signs, $15.7 \%$ still had moderate deficits, $10.4 \%$ had weakness in more than two limbs and $5.4 \%$ were dead. The remaining 67 cases were lost for follow-up.

A $5.4 \%$ death was recorded in the whole country: $2.7 \%$ in the southeast, $4.3 \%$ in the middle west, $5.9 \%$ in the south, $7.3 \%$ in the north and $7.6 \%$ in the northeast (Fig 5).

The age of the patients was related to the persistence of motor deficit at the second examination 60 days later: the older was the child, the worst the prognosis as shown by the $29 \%$ from the group of $0-4$ years, 31\% from $5-9$ years, and 35\% from $10-15$ years, that remained with moderated or severe motor deficit or were dead (Table 2).

The severity of the cases at the first examination represented a bad prognostic factor related both to the death rate and the persistence of moderated or severe motor deficit at the second examination. From those cases presenting at the first examination with moderated motor deficit at the follow up, $20 \%$ will present with moderated or severe motor deficit and $3.2 \%$ will be dead at 60 days later. From the severe cases at entrance, up to $33 \%$ will present at 60 days later with moderate or severe deficit and $8.2 \%$ will be dead. Those cases presenting with mild or moderate motor deficit at the first examination more frequently 
had a favorable outcome with absence of motor deficit at the second examination, sixty days later (Table 2).

An association was looked for between the length of time for installation of Guillain-Barré syndrome and its prognosis at the second examination. The group of patients with a prodromal period greater than 15 days (6\%) had a better outcome with $62 \%$ without sequelae, $10 \%$ of mild weakness, $11 \%$ with moderate deficit and $9 \%$ of severe weakness. From the group that developed the motor deficit between 8 to 14 days $(6.5 \%)$ there were $53 \%$ without sequelae, $7 \%$ mildly affected, $17 \%$ with moderate weakness and $12 \%$ of severe deficit at 60 days later. From the third group (88\%) that took 0 to 7 days to start the weakness $57 \%$ had no motor signs at sixty days after the first examination, $7 \%$ had mildly weakness, $16 \%$ moderate weakness and $10 \%$ severe deficit. The death rates for the first group cited above was $4 \%$ for the second $5 \%$ and $6 \%$ for the last one. There were $3 \%, 6 \%$ and $4 \%$ of lost cases in the follow-up respectively (Table 2 ).

\section{DISCUSSION}

This study was based on data gathered during the Brazilian program of poliomyelitis surveillance. Therefore, the strength of the result is based on the numbers of observations, typical of epidemiological surveys, and not in the accuracy of individual data. The diagnosis of GBS was mostly based on clinical grounds as applied by other epidemiological studies $^{4,5}$ and sometimes need to be confirmed on the follow up. Indeed, it has been recognized that laboratory tests are not necessary to establish the diagnosis of GBS, but rather to exclude other conditions ${ }^{6}$. In the present study, laboratory tests were used to exclude the diagnosis of poliomyelitis and other virus diseases, according to the recommendations of the World Health Organization.

Incidence - The GBS incidence rate of 0.46 per 100,000 children we found is somewhat different from that obtained in China ${ }^{4}$, where a much wider band of rates was observed, 0.13 to 1.26 per 100,000 children. Also it is different from that cited for the Latin America as a whole 0.91 to 1.1 cases per 100,000 children younger than 15 years old 7,8 and $0.95 / 100,000$ children less than 12 years of age at risk in Kuwait ${ }^{9}$. It is worthwhile to emphasize that the epidemiological studies are influenced by the epidemiological criteria adopted and that the Guillain-Barré variants cases can be missed when only the typical cases are allowed to enter in the analysis. Our data on incidence rates in the whole country
(0.46 per 100,000$)$ and for the different macro regions $(0.4$ to 0.6 per 100,000$)$ are similar of those derived from the studies in USA that is calculated as 0.2 to 0.5 per 100,000 children less than 15 years old ${ }^{10}$ being important to remark that this was a population-based study with a largest number of children included. Also our data are similar to those from Finland $(0.38$ per 100,000$)$ in children younger than 15 years of age ${ }^{11}$ and is not different of 0.6 per 100,000 recorded in California 5 . The incidence should be actually a little higher if one consider the clinical variants of GBS which has not been included in our data, as the Miller-Fisher cases could be under the term ataxia disregard in "others" at the begin of our study. In other studies the variants other than MillerFisher are responsible for $0.14 / 100,000 /$ year and $0.09 / 100,000 / y e a r$ for the typical Miller Fisher syndrome, as has been shown previously. ${ }^{12,13}$ On the other hand the variants accounted for about $7 \%$ to $8.2 \%$ of the $\mathrm{GBS}^{14}$ and would be less common in children than in adults ${ }^{15}$.

Seasonal distribution - It was not demonstrated a clear seasonal distribution of the cases of GBS, although a tendency for clustering was observed in some areas (Fig 2). This observation is rather different from the observed in northern China with a clear correlation with the summer months for the Acute Motor Axonal Neuropathy (AMAN) type of GuillainBarré, ${ }^{16}$ and in other regions such as in Argentina with two peaks for both forms of the disease Acute Demyelinating Peripheral Neuropathy (AIDP) and AMAN at the summer and at the winter months ${ }^{7}$.

Age distribution - The peak incidence in 2 yearsold children, and the frequency of persistence of motor deficit 2 months after the diagnosis was established, were comparable in both studies, $20-30 \%$ in China and 33\% in Brazil. The higher incidence in children at two years of age had been shown, and found also that these taxes remained high at 3 and 4 years old ${ }^{5}$. The variation of incidence by age could suggest different susceptibility to the triggering factors. Our results are different from those of the adult groups where usually is shown that the incidence increases with age, and ours seems to decrease until 15 years of age, suggesting two peaks of incidence.

Sex distribution - Our results showed a slight, not significant, male preponderance of GBS, as has been found in some series ${ }^{15,17}$ but not in others ${ }^{9}$. We also showed a lack of association between the length of time for installation of GBS and the severity of its outcome, which indicates that in our series this could not be considered as a prognostic factor. 
It is reported that it is not possible to predict future motor deficit at an early examination ${ }^{18}$, but our results suggested that moderate cases at the first examination had a better prognosis at sixty days (64.8\% without sequalae), compared to the severe cases $(48 \%)$. Also the length of time to develop the first motor signs were related to the outcome, the slowly the better (Table 2).

The death rate of $5.4 \%$ we found is comparable to that of other series of pediatric $\mathrm{GBS}^{17}$, and its regional variation probably reflects the quality of available local health services. Nonetheless in Southeast England a recent survey had showed that the mortality rate is still high as $8 \%$ in spite of being a region of a high standard medical care quality, without much change from previous data of 5 to $10 \%{ }^{19}$ but not for others that reported a fall in $2 \%$ to $3 \%$ over the past 40 years mainly through improvements in nursing and critical care measures, and early use of plasmapheresis or high dose intravenous immunoglobulin ${ }^{20}$.

There were data from Finland in children ${ }^{21}$ and adults ${ }^{22}$ and from Kuwait ${ }^{9}$ that explored the relationship between the Guillain-Barré syndrome and the oral polio vaccine and we though in exploring also this possibility. Our data do not confirm the correlation between oral polio vaccine administration and the Guillain-Barre syndrome during the years studied. The same conclusion as shown by the others data $^{23}$ that showed the rise of numbers of GB cases have started before the immunization campaign, so without a temporal relationship. Also the same conclusion was arrived in Kuwait ${ }^{9}$, and in Latin America ${ }^{24}$. Sallisbury ${ }^{25}$ says that to reconcile the data from Finland and those from Americas it will blame the previous Intramuscular (IPV) plus oral (OPV) to trigger the GBS, but this is not proved. Others vaccine were linked to GBS but this had being merely on temporal association, only the link with rabies vaccines are not controversial. For the epidemics followed the swine flue influenza vaccine, there is a consensus of expert concluding that a small risk of developing GBS exist for up to 6 weeks after immunization ${ }^{26}$.

Acknowledgments - We thank Dr. Carlos Eduardo Tosta and Dr. Pedro Tauil for thoughtful discussions and criticism. We also thank Ms Sara Jane Medeiros and Mr Paulo Cesar Teixeira from Fundação Nacional de Saúde for making available the data from surveillance of AFP program, and Mrs Selma S. Kuckelhaus for her precious collaboration.

\section{REFERENCES}

1. Lasky T. Methodologic issues in clinical research: the example of Guillain-Barré syndrome. Neuroepidemiology 1996;15:57-61.

2. Ho TW, Mishu B, Li CY, et al. Guillain-Barré syndrome in northern China: relationship to Campilobacter jejuni infection and anti-glycolipid antibodies. Brain 1995;118:597-605.

3. Pedro-Cuesta J, Abraira V, Jiang G-X, Solders G, Fredrikson S. GuillainBarré syndrome in south-west Stockholm, 1973-91,3. Clinicoepidemiological subgroups. Acta Neurol Scand 1996;93:175-83.

4. Chiba $\mathrm{Y}, \mathrm{Xu} \mathrm{A}, \mathrm{Li} \mathrm{L}$, et al. Poliomyelitis surveillance in Shandong Province, China, 1990-92; WHO Bull 1994;72:915-920.

5. Rantala H, Cherry J D, Shields W D, Uuhari M. Epidemiology of Guillain-Barré syndrome in children: relationship of oral polio vaccine administration to occurrence. J Pediatr 1994;124:220-223

6. Van der Meché FG. The Guillain-Barré syndrome: pathogenesis and treatment. Rev Neurol 1996;152:355-358.

7. Paradiso G, Tripoli J, Galicchio S, Fejerman N. Epidemiological, clinical, and electrodiagnostic findings in childhood Guillain-Barré syndrome: a reapraisal. Ann Neurol 1999;46:701-707.

8. WHO-AIREN. Acute onset flaccid paralysis. Geneva: WHO, 1993:993.3

9. Ismail EAR, Shabani IS, Badawi M. et al. An epidemiologic, clinical, and therapeutic study of childhood Guillain-Barré syndrome in Kuwait: it is related to the oral polio vaccine? J Child Neurol 1998;13:488-492.

10. Hurwitz E S, Holman RC, Nelson DB, Schonberger LB. National surveillance for Guillain-Barré syndrome: January 1978 to March 1979. Neurology 1983; 33:150-157.

11. Rantala H, Uhari M, Niemela M. Occurrence, clinical manifestation, and prognosis of Guillain-Barré syndrome. Arch Dis Child 1991; 66:706-708.

12. Emilia-Romagna Study Group on Clinical and Epidemiological Problems in Neurology. Guillain-Barré syndrome in Emilia-Romagna, Italy,1992-3: incidence, clinical features, and prognosis. J Neurol Neurosurg Psychiatry, 1998;65:218-224.

13. Ropper AH. Unusual clinical variants and signs in Guillain-Barré syndromne. Arch Neurol 1986;43: 1150-1152.

14. Shuaib A, Becker WJ. Variants of Guillain-Barré syndrome? Miller Fisher syndrome, facial diplegia, and multiple cranial nerve palsies. Can J Neurol Sci 1987;14:611-616.

15. Evans OB, Vedanarayanan V. Guillain-Barré syndrome. Pediatr Review 1997;18:1-13.

16. McKhann GM, Cornblath DR, Griffin JW, et al. Acute motor axonal neuropathy: a frequent cause of acute flaccid paralysis in China. Ann Neurol 1993; 33:333-342.

17. Ropper AH, Wijdicks EFM, Truax BT. Guillain-Barré syndrome. Philadelphia: FA Davis,1991.

18. Sedano M J, Calleja J, Canga E, Berciano J. Guillain-Barré syndrome in Cantabria, Spain. epidemiological and clinical study. Acta Neurol Scand 1994;89:287-292.

19. Rees JH, Thompson RD, Smeeton NC, et al. Epidemiological study of Guillain Barré Syndrome in South East England (UMDS Guy's Hosp, London). J Neurol Neurosurg Psychiatry 1999:64:74-77.

20. Asbury AK. Guillain-Barré syndrome. In Stern MB, Brown MJ, Galetta SL, Asbury AK (eds). Penn neurology 2000: management of common neurologic problems. Irvington: Alpha Medica Press, 200:99-114.

21. Uhari M, Rantala H, Niemela M. Cluster of childhood Guillain-Barré cases after na oral polio vaccine campaign. Lancet 1989;2:440-441

22. Kinnunen E, Farkkila M, Hovi T, et al. Incidence of Guillain-Barré syndrome during a nationwide oral poliovirus vaccine campaign. Neurology 1989:39:1034-1036.

23. Kinnunen E, Junttila O, Haukka J, Hovi T. Nationwide oral poliovirus vaccination campaign and the incidence of Guillain-Barré syndrome. Am J Epidemiol 1998;147:69-73.

24. Olive J-M, Castillo C, Castro RG, Quadros CA. Epidemiologic study of Guillain-Barré syndrome in children $<15$ years of age in Latin America. J Infect Dis 1997:175 (Suppl): S160-164

25. Sallisbury DM. Association between oral poliovaccine and GuillainBarré syndrome? Lancet 1998;351:79-80.

26. Safranek TJ, Lawrence DN, Kurland. R, et al. Reassessment of the association between Guillain-Barré syndrome and receipt of swine influenza vaccine in 1976-1977: results of a two-state study. Am J Epidemiol 1991;133:940-951. 